\title{
Território da mesorregião geográfica Sudeste Paranaense: o escopo e a espacialidade dos indicadores sociais e educacionais
}

Reinaldo Knorek ${ }^{1}$

Ancelmo Schöner ${ }^{2}$

Rui Pedro Julião ${ }^{3}$

\begin{abstract}
Resumo
Este artigo se fundamenta na área do desenvolvimento regional, baseada em análises no escopo dos indicadores sociais e educacionais, nos delimites do território da Mesorregião Geográfica Sudeste Paranaense. Porquanto, a análise na espacialidade é sobre os dados divulgados nos três últimos Censos do IBGE (1991-2000-2010). De tal modo, esse Território é configurado por 21 municípios, foco do estudo, que está dividido geograficamente em quatro microrregiões: 1) Microrregião Geográfica Prudentópolis. 2) Microrregião Geográfica Irati, 3) Microrregião Geográfica União da Vitória e; 4) Microrregião Geográfica São Mateus do Sul. Essa microrregião se caracteriza por possuir: baixo Índice de Desenvolvimento Humano Municipal (IDHM), grande número de beneficiários da política pública do Programa Bolsa Família (PBF), baixo dinamismo econômico na geração de emprego e renda, pouco dinamismo industrial e tendo como principal atividade econômica a exploração agropecuária, principalmente, em atividades associadas à agricultura familiar $\mathrm{O}$ método aplicado é o exploratório-descritivo, tendo como base a coleta dos dados divulgados pelos censos, na apreciação do recorte territorial. Conclui-se, na apreciação que a espacialidade territorial passa por uma evolução medida e observada em porcentagens, visto que os indicadores educacionais revelam na análise territorial, a contribuição para o desenvolvimento social e comunitário na mesorregião geográfica Sudeste Paranaense.
\end{abstract}

Palavras-chave: território, indicadores, educação, desenvolvimento regional e comunitário.

\section{Territory of the Sudeste Paranaense geographic region: the scope of spatiality and educational indicators}

\begin{abstract}
This article is based on the area of regional development, based on analyses in the scope of social and educational indicators, in the boundaries of the territory of the Southeast Paraná Geographic Mesoregion. Because the spatiality analysis is about the data published in the last three IBGE Censuses (1991-2000-2010). Thus, this Territory is configured by 21 municipalities, the focus of the study, which is geographically divided into four microregions: 1) Prudentópolis geographic microregion. 2) Irati geographic microregion, 3) União da Vitória geographic microregion and; 4) São Mateus do Sul geographic microregion. This micro-region is characterized by having: low Municipal Human Development Index (IDHM), large number of beneficiaries of the public policy of the Bolsa Família Program (PBF), low economic dynamism in the generation of employment and income, little industrial dynamism and having as main economic activity agricultural exploitation, mainly in activities associated with family agriculture. The method applied is exploratory-descriptive, based on the collection of data disclosed by the censuses, in the assessment of the territorial cutout. It is concluded, in the assessment that territorial spatiality goes through an evolution measured and observed in percentages, since the educational indicators reveal in the territorial analysis, the contribution to social and community development in the Southeast geographic mesoregion of Paraná.
\end{abstract}

Keywords: Territory, Indicators, Education, Regional and Community Development.

\footnotetext{
${ }^{1}$ Doutor em Engenharia de Produção (UFSC) e Pós-Doutor em Geografia e Desenvolvimento Regional (Universidade Nova de Lisboa) e Pós-Doutorando em Desenvolvimento Comunitário na Unicentro-PR. reinaldok@gmail.com

2 Doutor e Pós-Doutor em História (UFF) e Pós-Doutor em Desenvolvimento Regional (UNISC). Professor do Programa de Pós-Graduação em História e do Programa de Pós-Graduação em Desenvolvimento Comunitário da Unicentro-PR. ancelmo.schorner13@gmail.com

3 Doutor em Geografia e Planeamento Regional. Professor do Programa de Pós-Graduação em Geografia e Planeamento Regional (PGPR-FCSH) da Universidade Nova de Lisboa. rpj@fcsh.unl.pt
} 


\section{Introdução}

Nas discussões e enfoques, das mais distintas escalas espaciais, sobre as ação e transformação no escopo de um território, nas mais diferentes dimensões setoriais presentes, além de formulações e planejamento das políticas públicas, destaca-se aqui a área da educação, sobretudo, como reflexão sobre espacialidade e o desenvolvimento territorial, regional e comunitário. A educação é um dos condicionantes aos desafios e contradições geradas, por estruturas preparadas, voltadas para a promoção das políticas públicas de coesão e transformações territoriais. Os processos, conteúdos e dimensões territoriais - rurais e urbanas que ao longo da história formaram um território, como por exemplo, os que incidiram no sudeste paranaense, pode-se dizer que foram de certa forma, influenciados pelas estruturas educacionais desenvolvidas no mesmo e, voltadas na formação das pessoas para promoverem o desenvolvimento comunitário, e isso foi acontecendo de forma concisa e gradual.

Dentre tantas políticas públicas e programas de governo, voltados ao desenvolvimento comunitário, territorial e regional, destaca-se aqui, todavia não sendo uma política pública de Estado, mas sim um Programa de Governo, o - Programa Território da Cidadania (PTC) - lançado em 2008 pelo Governo Federal, de Luiz Inácio Lula da Silva, visto que, aproximar-se do desenvolvimento territorial no Brasil. Para Knorek, (2017, p. 163), este programa de governo, teve como principal objetivo alavancar o desenvolvimento econômico e universalizar os programas básicos de cidadania, em territórios com baixo dinamismo econômico e social existente no Brasil. Por mais de nove anos muitos projetos foram implantados, nestes 264 territórios, definidos como subdesenvolvidos no Brasil, donde os resultados poderão ser analisados num futuro, como eficientes ou não, para o desenvolvimento territorial e comunitário.

Logo, a partir de diagnósticos constituídos por meio de dados estatísticos, esses territórios, classificados conforme o decreto presidencial e definiu-se condições para que os mesmos fossem incluídos no Programa Territórios da Cidadania, entre eles destaca-se: o baixo Índice de Desenvolvimento Humano Municipal (IDHM), grande número de beneficiários da política pública do Programa Bolsa Família (PBF); assentamentos da reforma agrária; maior concentração de populações quilombolas e indígenas e territórios com maior número de municípios com baixo dinamismo econômico na geração de emprego e renda, pouco dinamismo industrial e tendo como principal atividade econômica a exploração agropecuária, principalmente, as atividades conexas à agricultura familiar. 
Para alguns territórios brasileiros, foi elaborado a Política Nacional de Desenvolvimento Regional (PNDR) que circunscreveram a origem do programa Território da Cidadania. Assim as políticas públicas de desenvolvimento comunitário, territorial ou regional, tendo como objetivos promover o desenvolvimento econômico e universalizar programas básicos de cidadania por meio de estratégias, aqui em destaque as educacionais voltadas na promoção da formação das pessoas para o desenvolvimento territorial e comunitário de forma sustentável. A participação social e a integração de ações entre Governo Federal, Estados e Municípios são fundamentais para a construção dessa estratégia (BRASIL, 2018).

O exemplo citado, dos Territórios da Cidadania, que se configuravam com 1851 municípios, 33,2\% do total dos municípios brasileiros, e que vivem nesses Territórios da Cidadania 44,6 milhões de brasileiros (as), abrangendo 53,17\% da superfície nacional. Neles encontra-se $42 \%$ da demanda social do Ministério do Desenvolvimento Agrário (MDA), constituído por agricultores (as) familiares, assentados (as) pela reforma agrária, trabalhadores (as) rurais que buscam acesso à terra, além de outros segmentos de populações tradicionais que habitam os espaços rurais. Visto que essa política de desenvolvimento territorial, que estava sob a coordenação do Ministério do Desenvolvimento Agrícola (MDA), porquanto, pelo Decreto no 8.865, de 29 de setembro de 2016, o governo Temer, transfere a Secretaria Especial de Agricultura Familiar e do Desenvolvimento Agrário para a Casa Civil da Presidência da República e dispõe sobre a vinculação do Instituto Nacional de Colonização e Reforma Agrária - INCRA e decreta o "fim" dos Territórios da Cidadania no Brasil. Com isso foram eliminados muitos dados construídos por vários estudos territoriais sobre projetos e suas aplicações voltadas ao desenvolvimento econômico e social. Os territórios demarcados como os da Cidadania são, portanto, territórios formados, por um conjunto de municípios, com as mesmas características, por conseguinte, se destacam: o econômico, educacional, o ambiental, a identidade e coesão social, a cultural e espaços geográficos.

Para este estudo, especificamente, o escopo está no território sudeste paranaense tendo um recorte do Território Da Mesorregião Geográfica Sudeste Paranaense. Esse Território é configurado por 21 municípios, foco do estudo, que está dividido geograficamente em quatro microrregiões: 1) - Microrregião Geográfica Prudentópolis: Fernandes Pinheiro, Guamiranga, Imbituva, Ipiranga, Ivaí, Prudentópolis, Teixeira Soares. 2) - Microrregião Geográfica Irati: Irati, Mallet Rebouças, Rio Azul; 3) - Microrregião Geográfica União da Vitória: Bituruna, Cruz Machado, General Carneiro, Paula Freitas, Paulo Frontin, Porto Vitória, União da Vitória; 4) - 
Microrregião Geográfica São Mateus do Sul: Antônio Olinto, São João do Triunfo, São Mateus do Sul.

Os mesmos se caracterizam por possuírem: baixo Índice de Desenvolvimento Humano Municipal (IDHM), grande número de beneficiários da política pública do Programa Bolsa Família (PBF), baixo dinamismo econômico na geração de emprego e renda, pouco dinamismo industrial e tendo como principal atividade econômica a exploração agropecuária, principalmente, em atividades associadas à agricultura familiar. Neste recorte apresenta-se e analisa-se a demografia, IDHM, os dados estatísticos educacionais que apontam indicadores educacionais neste espaço geográfico, como os de ensino fundamental completo, ensino médio completo e o ensino superior completo.

\section{Infraestruturas educacionais e desenvolvimento}

Para entender as infraestruturas educacionais, segundo Libâneo (2008), as construções, os mobiliários e o material didático precisam ser adequados e suficientes para assegurar o desenvolvimento do trabalho pedagógico e favorecer a aprendizagem. A educação com qualidade social e a democratização, conforme o CONAE (2010) implica longo, na garantia do direito à educação para todos, por meio de políticas públicas, materializadas em programas e ações articuladas, com acompanhamento e avaliação da sociedade. Articular um processo educativo, de modo a favorecer o desenvolvimento e a apreensão de saberes científicos, artísticos, tecnológicos, sócio históricos, compreendendo, assim, as necessidades do mundo do trabalho, os elementos materiais e a subjetividade humana (BRASIL, 2010).

Vieira, (2001), em sua obra Estrutura e Funcionamento da Educação Básica, conceituam que estrutura e o funcionamento de uma escola dizem respeito à organização do sistema escolar. A infraestrutura educacional leva em conta também as tecnologias nas salas de aula. Como afirma Vieira, "a busca pela estrutura e funcionamento pleno é um desafio permanente para os que trabalham neste âmbito da atuação humana" (VIEIRA, 2001, p. 22). Estrutura se refere aos prédios, instalações físicas, como bibliotecas, laboratórios, sala de aula, quadra, banheiro, etc. Em relação ao funcionamento por sua vez, depende da sua estrutura, isto é, uma escola em funcionamento tem a presença de funcionários, professores, alunos, diretores, coordenadores, etc. Mas, a referida autora enfatiza que para o bom funcionamento da escola é preciso o compromisso de todos com a aprendizagem, do contrário ela não se encontrará nesse nível. Promover educação, como observado, requer a garantia de um ambiente com condições para 
que a aprendizagem possa ocorrer. Dessa forma é importante proporcionar um ambiente físico, aqui denominado infraestrutura escolar que estimule e viabilize o aprendizado, além de favorecer as interações humanas. Dessa forma, "fica transparente a necessidade de políticas públicas que visem a diminuir as discrepâncias e promover condições escolares mínimas para que a aprendizagem possa ocorrer em um ambiente escolar mais favorável [...]" (SOARES NETO, et al, 2013, p. 78).

Logo, a infraestrutura no setor educacional, contribui para que o desenvolvimento aconteça, e assim, os investimentos nos mais diversos territórios no Brasil, como os Territórios da Cidadania, extintos pelo governo Temer em 2016 e, também estão classificados pelo IBGE, como o Território Da Mesorregião Geográfica Sudeste Paranaense, donde, certamente resultam indicadores educacionais que podem ser favoráveis ou não, para o desenvolvimento comunitário do território.

A infraestrutura educacional, diz respeito ao prédio escolar, aos mobiliários, aos recursos tecnológicos, entre outros, que auxiliam os professores e alunos a uma educação pertinente. Toda essa estrutura associada ao capital humano, pode com certeza levar pela promoção da formação das pessoas, um território ao crescimento e ao desenvolvimento comunitário: em todas as áreas, desde o educacional pela formação do cidadão, cultural, econômico, ambiental entre tantas outras.

\section{Indicadores demográficos no território Sudeste Paranaense}

Desde meados da década de 60, do século XX, que os chamados indicadores sociais têm vindo ser objeto de atenção crescente de decisões públicas, acadêmicos e comunicação social e pesquisas territoriais de desenvolvimento. Segundo (ALTMANN, 1981, p. 187-204.), a expressão “indicadores sociais" surgiu nos EUA em 1966, tendo sido veiculada numa obra coletiva organizada por Raymond Bauer, intitulada Social Indicators. A finalidade desse estudo consistiu em avaliar os impactos da corrida espacial na sociedade americana. A observação da mudança na sociedade em termos socioeconômicos, dada a precariedade dos dados existentes, só pôde ser contornada por Bauer e seus colegas através da construção de indicadores de caráter social; esse fato permitiu uma análise aprofundada do conjunto das condições sociais, políticas, econômicas e teóricas

De acordo com (SANTAGADA, 2007, p. 113-114) o interesse pelos indicadores sociais expandiu-se na década de 1970, tendo decaído nos anos 80 e revitalizado na década seguinte. 
Em especial a partir do lançamento do projeto do IDH, no início dos anos 90 do mesmo século, os argumentos sobre a necessidade de se medir o avanço da sociedade e o desempenho da gestão pública deslocaram-se da área econômica para áreas tão diversas como a saúde, a educação, a cultura, os direitos humanos e o meio ambiente. A escolha da informação que retrata o estado social de uma área geográfica é uma tarefa difícil, porque depende de acordo entre governantes, políticos em geral e organizações da sociedade civil (Associações cívicas, Sindicatos, Associações patronais, dentre outros) acerca dos critérios mais importantes para se formular os indicadores.

Atualmente já existe um consenso sobre os critérios de seleção da informação que melhor retrata o estado social de uma área geográfica, podendo fazer-se menção a um conjunto mínimo de Indicadores Sociais. Esse conjunto é composto por informações sobre: i) as características da população, ii) a dinâmica demográfica, iii) o trabalho e o rendimento; iv) saúde, v) justiça e segurança pública, vi) educação e, vii) condições de vida das famílias.

Santos em sua alocução, sobre a heterogeneidade do espaço habitado, caracteriza o espaço habitado em três dados essenciais:

A evolução global da população mundial só pode ser completamente entendida se considerarmos ao menos três dados essenciais. Primeiro, a distribuição da população entre as diversas áreas do Globo e dentro de cada país evolui de maneira desigual. Depois com isso não é apenas o resultado do excesso de nascimentos sobre as mortes, temos de levar em conta as migrações internas e internacionais, cada vez mais frequentes (...) uma das características do espaço habitado é pois, sua heterogeneidade, seja em termos da distribuição numérica...seja em termos de sua evolução. Aliás, essas duas dimensões escondem e incluem outra: a enorme diversidade qualitativa sobre a superfície da terra, quanto a raças, culturas, credos, níveis de vida, etc. (SANTOS, 1997, p.39)

Segundo JANNUZZI (2001, p 10), foi-se o tempo em que políticos e administradores públicos podiam alardear suas realizações sem que pudesse aferir o impacto que haviam causados às coletividades que governa. Os indicadores, particularmente os sociais ficavam guardados para e pelos especialistas. A situação vem mudando e hoje é obrigatória a referência aos indicadores de situação, desempenho e de resultados para qualquer programa ou atividade pública. Os indicadores sociais são insumos básicos e indispensáveis em todas as fases do processo de formulação e implementação das políticas públicas. Em cada fase do processo de formulação e implementação da política pública requer emprego de indicadores.

Prontamente os recursos empregados, métodos de alocação de recursos, resultados, etc. devem ser avaliados por meio de indicadores adequados que demonstrem a realidade da sociedade em análise. Logo, na educação os dados produzidos pelos censos do IBGE, são usados 
para formular indicadores e contribuem para a tomada de decisões na execução e formulação de políticas públicas educacionais. Eles indicam a evolução, crescimento ou decréscimo, em números, da realidade de um espaço ocupado. Quando se quer compreender como está ocorrendo o desenvolvimento humano em um território, indicadores como o IDHM ${ }^{1}$, refletem a realidade, pois é obtido pela média geométrica dos três subíndices das dimensões que compõem o índice: longevidade, educação e renda.

Entender o Índice de Desenvolvimento Humano Municipal (IDHM), os subíndices que o compõem, relativos às dimensões Renda, Educação e Longevidade, além dos subíndices que compõem o índice da dimensão Educação (os índices das dimensões Renda e Longevidade são construídos a partir de um único indicador - renda per capita e esperança de vida ao nascer, respectivamente).

O IDHM Índice da dimensão Longevidade que é um dos 3 componentes. É obtido a partir do indicador Esperança de vida ao nascer, através da fórmula: [(valor observado do indicador) (valor mínimo)] / [(valor máximo) - (valor mínimo)], onde os valores mínimo e máximo são 25 e 85 anos, respectivamente. O IDHM Educação é o índice sintético da dimensão Educação que é um dos 3 componentes do IDHM. É obtido através da média geométrica do subíndice de frequência de crianças e jovens à escola, com peso de $2 / 3$, e do subíndices de escolaridade da população adulta, com peso de 1/3. Subíndice de escolaridade fundamental da população adulta - IDHM Educação, Subíndice selecionado para compor o IDHM educação, representando o nível de escolaridade da população adulta. É obtido pelo indicador da \% de jovens e adultos, com 18 anos ou mais, com o fundamental completo. Subíndice de frequência escolar da população jovem - IDHM Educação Subíndice selecionado para compor o IDHM educação, representando a frequência de crianças e jovens à escola em séries adequadas à sua idade. É obtido através da média aritmética simples de 4 indicadores: \% de crianças de 5 a 6 anos na escola, \% de crianças de 11 a 13 anos no 2 ㅇco ciclo do fundamental, \% de jovens de 15 a 17 anos com o fundamental completo e \% de jovens de 18 a 20 anos com o médio completo.

Já para o IDHM Renda o índice da dimensão Renda que é um dos 3 componentes do IDHM. É obtido a partir do indicador Renda per capita, através da fórmula: [In (valor observado do indicador) - In (valor mínimo)] / [In (valor máximo) - In (valor mínimo)], onde os valores mínimo e máximo são $R \$ 8,00$ e $R \$ 4.033,00$ (a preços de agosto de 2010). 
Para entender o desenvolvimento na espacialidade do território sudeste paranaense, os indicadores do IDHM, ajudam a verificar por números essa evolução. Na Tabela 1 é apresentado o IDHM dos últimos 3 censos demográficos realizados pelo IBGE.

Tabela 1 - Dados do IDHM do Brasil, Paraná e do Território Sudeste (PR)

\begin{tabular}{lrrr}
\hline Espacialidades & IDHM 1991 & IDHM 2000 & IDHM 2010 \\
\hline Brasil & 0,493 & 0,612 & 0,727 \\
\hline Paraná & 0,507 & 0,650 & 0,749 \\
\hline Antônio Olinto & 0,317 & 0,495 & 0,656 \\
\hline Bituruna & 0,392 & 0,533 & 0,667 \\
\hline Cruz Machado & 0,328 & 0,492 & 0,664 \\
\hline Fernandes Pinheiro & 0,333 & 0,526 & 0,645 \\
\hline General Carneiro & 0,381 & 0,532 & 0,652 \\
\hline Guamiranga & 0,361 & 0,511 & 0,669 \\
\hline Imbituva & 0,395 & 0,540 & 0,660 \\
\hline Ipiranga & 0,335 & 0,519 & 0,652 \\
\hline Irati & 0,459 & 0,617 & 0,726 \\
\hline Ivaí & 0,366 & 0,536 & 0,651 \\
\hline Mallet & 0,424 & 0,575 & 0,708 \\
\hline Paula Freitas & 0,439 & 0,592 & 0,717 \\
\hline Paulo Frontin & 0,397 & 0,545 & 0,708 \\
\hline Porto Vitória & 0,409 & 0,558 & 0,685 \\
\hline Prudentópolis & 0,390 & 0,544 & 0,676 \\
\hline Rebouças & 0,383 & 0,559 & 0,672 \\
\hline Rio Azul & 0,392 & 0,538 & 0,687 \\
\hline São João do Triunfo & 0,325 & 0,503 & 0,629 \\
\hline São Mateus do Sul & 0,434 & 0,599 & 0,719 \\
\hline Teixeira Soares & 0,409 & 0,575 & 0,671 \\
\hline União da Vitória & 0,521 & 0,663 & 0,740 \\
\hline Fonte:Attas Brail/2013, & & \\
\hline
\end{tabular}

Fonte: Atlas Brasil/2013, Dados da Pesquisa, 2019

Os IDHM dos municípios do território sudeste paranaense, como: Antônio Olinto, Bituruna, Cruz Machado, Fernandes Pinheiro, General Carneiro, Ipiranga, Ivaí, Rebouças, São João do Triunfo - melhoraram seus índices, praticamente dobrando os dados para melhor. Porém, somente Irati, São Mateus do Sul e União da Vitória chegaram próximos aos indicadores do Paraná e da média nacional. Faltam muitas realizações neste território para melhorar e superar esses indicadores de média estatual e nacional.

Segundo o levantamento, (IBGE, 2020) de acordo com as faixas de desenvolvimento humano municipal no Brasil, atualmente com Alto Desenvolvimento Humano, melhorou sua classificação em relação às edições anteriores. Em 2000 registrava Médio Desenvolvimento 
Humano e em 1991, Muito Baixo Desenvolvimento Humano. Cerca de 74\%, dos municípios brasileiros se encontram nas faixas de Médio e Alto Desenvolvimento. O restante, 25\%, está entre aqueles que apresentaram Baixo ou Muito Baixo Desenvolvimento Humano, um total de 1.431. A região Nordeste ainda é a que concentra o maior número de municípios no grupo de Baixo Desenvolvimento Humano (61,3\%). No Norte do país estes somam 40,1\%. Entre as que registram o maior número de municípios na faixa de Alto Desenvolvimento Humano estão as regiões Sul $(64,7 \%)$ e Sudeste $(52,2 \%)$. O Centro-Oeste e o Norte aparecem como as regiões com maior número de municípios classificados com Médio Desenvolvimento Humano. Registraram, respectivamente, $56,9 \%$ e $50,3 \%$ nesta categoria.

Posto que, para entender os indicadores demográficos, dentro de um espaço geográfico, pelo motivo que ajudam a compreender certas características do lugar habitado na a apreciação de espacialidade e dos dados, como na análise sobre indicadores educacionais, divulgados nos Censos do IBGE (1991, 2000 e 2010), especificamente, no recorte do território da mesorregião geográfica Sudeste Paranaense (TMGSP), certamente, leva-se a perceber a importância da ocupação desse espaço e da mobilidade populacional em busca de desenvolvimento e crescimento. Essa espacialidade territorial sudeste paranaense, já referenciado, se configura por 21 municípios, divididos geograficamente em quatro microrregiões: 1) Microrregião geográfica de Prudentópolis; 2) Microrregião geográfica de Irati; 3) Microrregião geográfica de União da Vitória; e 4) Microrregião geográfica de São Mateus do Sul.

Na Tabela 2 são apresentados os dados demográficos totais dos espaços ocupados no Brasil, Paraná e no Território Sudeste Paranaense. Apresentam em 20 anos a mobilidade populacional, em que, análises podem apontar e investigar as principais causas das mudanças nesse território. Os dados estimados para 2018 da população no país, Estado do Paraná e os municípios inseridos no território sudeste paranaense apontam certa estagnação na mobilidade e crescimento populacional do território em análise.

Segundo o IBGE (2019), os dados demográficos apresentados na Tabela 2, demonstram que a população brasileira cresceu 29,92\% no período de 1991 para 2010, enquanto o Estado do Paraná, nesse mesmo período, a população, cresceu 23,62\%. O território Sudeste Paranaense, conforme os dados desse mesmo período, a população total cresceu $16,15 \%$, abaixo da média paranaense e nacional.

Com relação à estimativa total da população em 2018, observa-se que no Brasil, de 2010 para 2018 teremos um aumento de 9,29\%, no Estado do Paraná terá um aumento populacional 
de $8,65 \%$ e no território sudeste paranaense o aumento populacional será de $7,42 \%$, sendo assim, será um crescimento inferior em nível de Brasil e Paraná.

Tabela 2 - Dados demográficos do Brasil, Paraná e do Território Sudeste (PR)

\begin{tabular}{lrrrr}
\hline & \multicolumn{4}{c}{ População total } \\
\hline \multicolumn{1}{c}{ Espacialidades } & 1991 & 2000 & \multicolumn{1}{c}{2010} & 2018 (estimativa) \\
\hline Brasil & 146.825 .475 & 169.798 .885 & 190.755 .799 & 208.494 .900 \\
Paraná & 8.448 .713 & 9.563 .458 & 10.444 .526 & 11.348 .937 \\
\hline Antônio Olinto & 7.733 & 7.407 & 7.351 & 7.441 \\
Bituruna & 12.852 & 15.733 & 15.880 & 16.377 \\
Cruz Machado & 16.568 & 17.667 & 18.040 & 18.675 \\
Fernandes Pinheiro & 6.212 & 6.368 & 5.932 & 5.690 \\
General Carneiro & 11.287 & 13.899 & 13.669 & 13.735 \\
Guamiranga & 7.136 & 7.134 & 7.900 & 8.664 \\
Imbituva & 16.570 & 24.496 & 28.455 & 32.179 \\
Ipiranga & 12.590 & 13.308 & 14.150 & 15.092 \\
Irati & 48.964 & 52.352 & 56.207 & 60.357 \\
Ivaí & 12.058 & 11.899 & 12.815 & 13.791 \\
Mallet & 11.808 & 12.602 & 12.973 & 13.595 \\
Paula Freitas & 4.665 & 5.060 & 5.434 & 5.837 \\
Paulo Frontin & 6.558 & 6.565 & 6.913 & 7.321 \\
Porto Vitória & 4.541 & 4.051 & 4.020 & 4.068 \\
Prudentópolis & 46.173 & 45.344 & 48.792 & 51.961 \\
Rebouças & 12.948 & 13.663 & 14.176 & 14.851 \\
Rio Azul & 12.406 & 13.023 & 14.093 & 15.134 \\
São João do Triunfo & 12.320 & 12.418 & 13.704 & 14.996 \\
São Mateus do Sul & 33.138 & 36.569 & 41.257 & 45.806 \\
Teixeira Soares & 7.810 & 8.192 & 10.283 & 12.163 \\
União da Vitória & 43.240 & 48.522 & 52.735 & 57.111 \\
\hline Total do Território & 347.577 & 376.272 & 404.779 & 434.844 \\
\hline FonteAtlas Bry & & \\
\hline
\end{tabular}

Fonte: Atlas Brasil/2013 - Dados da pesquisa, 2019.

Destaca-se que o município de Fernandes Pinheiro desse território, apresentam dados da estimativa, que se confirmarem, com o novo censo, a sua população irá diminuirá $4,07 \%$ e o município de Porto Vitória projeta um aumento de 48 habitantes. Mais ainda, em 20 anos, ele diminuiu sua população dos 4.541 para uma projeção de 4.068 habitantes em 2018. Consoantes à demografia, os municípios que ocorreram decréscimo, na população total, foram os de: António Olinto menos 4,94\%, Fernandes Pinheiro menos 4,51\%, e Porto Vitória o maior índice que foi com menos $11,47 \%$. 
Com relação à estimativa total da população em 2018, observa-se que no Brasil, de 2010 para 2018 teremos um aumento de 9,29\%, no Estado do Paraná terá um aumento populacional de $8,65 \%$ e no território sudeste paranaense o aumento populacional será de $7,42 \%$, sendo assim, será um crescimento inferior em nível de Brasil e Paraná.

Destaca-se que o município de Fernandes Pinheiro desse território, apresentam dados da estimativa, que se confirmarem, com o novo censo, a sua população irá diminuir $4,07 \%$ e o município de Porto Vitória projeta um aumento de 48 habitantes. Mais ainda, em 20 anos, o município diminuiu sua população dos 4.541 para uma projeção de 4.068 habitantes em 2018 . Consoantes à demografia, os municípios que ocorreram decréscimo, na população total, foram os de: António Olinto menos 4,94\%, Fernandes Pinheiro menos 4,51\%, e Porto Vitória o maior índice que foi com menos $11,47 \%$.

Já os municípios que tiveram um acréscimo populacional no Território Sudeste Paranaense foram: Bituruna com mais 23,56\%, Cruz Machado com mais $8,88 \%$, Imbituva com maior crescimento populacional no território com mais $71,72 \%$, Irati com mais $14,79 \%$, Rebouças cresceu 9,48\%, Prudentópolis cresceu 6,06\%, General Carneiro cresceu 21,10\%, Rio Azul cresceu 13,59\%, Guamiranga cresceu 10,69\%, Ipiranga cresceu 12,39\%, Mallet cresceu 16,78\%, São Mateus do Sul com mais 24,50\%, Teixeira Soares com mais 31,09\% e, por fim, União da Vitória com 21,96\%. A importância de entender a demografia como indicador de desenvolvimento pode apontar para várias análises territoriais e, sobretudo, observa-se que neste território a população cresceu abaixo da média brasileira e estadual, ficando estagnada no seu crescimento.

Na Tabela 3 são apresentados os dados demográficos dos espaços - rural e urbano - no Brasil, Paraná e no Território Sudeste Paranaense. Apresentam em 20 anos uma mobilidade populacional de análises a serem investigadas as principais causas de mudanças nesse território. O êxodo rural acentuado em alguns municípios, a busca pela cidade como opção de crescimento econômico e de formação acadêmica, a exploração de minérios em alguns municípios são fatores que podem responder os motivos dessa mobilidade rural e urbana do território.

Conforme o IBGE (2019), os dados demográficos apresentados na Tabela 3, demonstram que a população brasileira na área rural em 20 anos diminuiu 16,75\%. O Estado do Paraná, a população rural diminuiu 31,94 \% - muito acima da média nacional. Já o território sudeste paranaense diminuiu sua população rural em 13,38 \%. Esses dados demonstram um acentuado êxodo rural tanto em nível nacional, como no Estado e no território sudeste paranaense; a busca da cidade como fator de melhoria da vida. 
Tabela 3 - Dados demográficos - rural e urbano do Território Sudeste (PR)

\begin{tabular}{lrrrr}
\hline Espacialidades & Pop. rural 1991 & Pop. rural 2010 & Pop. urbana 1991 & Pop. urbana 2010 \\
\hline Brasil & 35.834 .485 & 29.830 .007 & 110.990 .990 & 160.925 .792 \\
\hline Paraná & 2.250 .760 & 1.531 .834 & 6.197 .953 & 8.912 .692 \\
\hline Antônio Olinto & 7.115 & 6.664 & 618 & 687 \\
\hline Bituruna & 7.277 & 5.981 & 5.575 & 9.899 \\
\hline Cruz Machado & 14.095 & 11.983 & 2.473 & 6.057 \\
\hline Fernandes Pinheiro & 4.339 & 3.838 & 1.873 & 2.094 \\
\hline General Carneiro & 5.209 & 4.100 & 6.078 & 9.569 \\
\hline Guamiranga & 5.716 & 5.664 & 1.420 & 2.236 \\
\hline Imbituva & 10.116 & 10.567 & 6.454 & 17.888 \\
\hline Ipiranga & 9.376 & 9.261 & 3.214 & 4.889 \\
\hline Irati & 17.686 & 11.275 & 31.278 & 44.932 \\
\hline Ivaí & 9.100 & 8.186 & 2.958 & 4.629 \\
\hline Mallet & 6.280 & 5.403 & 5.528 & 7.570 \\
\hline Paula Freitas & 3.192 & 2.686 & 1.473 & 2.748 \\
\hline Paulo Frontin & 4.985 & 4.740 & 1.573 & 2.173 \\
\hline Porto Vitória & 1.649 & 1.785 & 2.892 & 2.235 \\
\hline Prudentópolis & 34.781 & 26.329 & 11.392 & 22.463 \\
\hline Rebouças & 7.552 & 6.671 & 5.396 & 7.505 \\
\hline Rio Azul & 9.200 & 9.081 & 3.206 & 5.012 \\
\hline São João do Triunfo & 9.490 & 9.656 & 2.830 & 4.048 \\
\hline São Mateus do Sul & 17.211 & 15.551 & 15.927 & 25.706 \\
\hline Teixeira Soares & 5.127 & 5.487 & 2.683 & 4.796 \\
\hline União da Vitória & 4.077 & 2.752 & 39.163 & 49.983 \\
\hline Total do Território & 193.573 & 167.660 & 154.004 & 237.119 \\
\hline Fonte:Atas Brail/2013, & & &
\end{tabular}

Fonte: Atlas Brasil/2013, Dados da Pesquisa, 2019.

Destaca-se que esse território tem características e vocação para exploração agropecuária, como principal fonte de renda, nos municípios dessa espacialidade sudeste paranaense. Assim sendo, o recorte do território sudeste paranaense os municípios com diminuição na população rural foram: Antônio Olinto menos 6,47\%, Bituruna menos 17,80\%, Cruz Machado menos 14,98\%, General Carneiro menos 20,19\%, Irati menos 36,24\%, Imbituva menos 4,45\%, Ivaí menos 10,11\%, Mallet menos 13,96\%, Paula Freitas menos 15,85\%, Prudentópolis menos $24,30 \%$, São Mateus do Sul menos 9,64\% e União da Vitória menos 32,49\%. São João do Triunfo, Imbituva, Porto Vitória e Teixeira Soares tiveram um pequeno aumento da população rural. Este último, em 20 anos, teve um acréscimo de 7,02 \% na população rural (Tabela 3).

Quanto a demografia urbana, destaca-se na tabela 3, o que ocorreu no período de 1991 à 2010, segundo o IBGE, o Brasil se transforma cada vez mais urbano, pois a população urbana cresceu em 20 anos 44,99\%, o Estado do Paraná cresceu 43,80\% e o recorte no território sudeste paranaense o acréscimo na população urbana foi de $53,69 \%$. 
Neste território os municípios que tiveram maior crescimento da população urbana foram: Antônio Olinto mais 11,16\%, Bituruna crescimento mais 77,56\%, Cruz Machado grande crescimento com mais $144,92 \%$, Imbituva o maior crescimento com 177,03\%, General Carneiro mais $57,43 \%$, Irati com mais 43,65\%, Ivaí com 56,49\%, Mallet com 36,93\%, Paula Freitas com 38,14\%, Prudentópolis com 97,185 também com alto crescimento urbano, São Mateus do Sul cresceu 61,39\% Teixeira Soares com 78,75\% e União da Vitória cresceu 23,62\%. Destaca-se que Porto Vitória com menos $22,09 \%$, foi o único município que diminuiu sua população urbana no território sudeste paranaense.

Destaca-se que os indicadores supracitados fazem parte das análises de desenvolvimento territorial que contribuem para o entendimento e importância dos indicadores educacionais como determinante para o desenvolvimento territorial e comunitário do sudeste paranaense.

\section{Indicadores educacionais no território Sudeste Paranaense}

Os indicadores educacionais, divulgados nos censos do IBGE (1991, 2000, e 2010) de forma comparativa, leva-se a compreender que está ocorrendo uma evolução ou melhora na área da educação, explana-se no quadro 1, que no Estado do Paraná, ao observar-se os dados produzidos pelos Censos, destaca-se que eles estão em conformidade com a média nacional no ensino fundamental completo, no ensino médio completo. Porém no ensino superior completo, os dados apontam uma leve porcentagem acima da média nacional. Para compreender os indicadores educacionais, no Quadro 1, apresentam-se indicadores gerais em nível de Brasil comparados ao do Estado do Paraná.

Certamente, esses dados apontam uma melhora no ensino superior completo do Estado do Paraná, mas indicam também que, nos anos de 2000 até 2010, ocorreu um aumento de $81,83 \%$ entre os indicadores que levam ao entendimento que está ocorrendo melhoras nessa área de ensino nesse território.

Para realizar uma análise dos indicadores educacionais na espacialidade do território do sudeste paranaense, reuniram-se dados estatísticos em forma de tabelas, sobre ensino fundamental completo, ensino médio completo e ensino superior completo. Afim de que, os dados estatísticos, gerados pelos Censos do IBGE (1991-2000-2010) são insumos para construção dos indicadores sociais educacionais, para tal entendimento, esse coletado foram nos delimite do território sudeste paranaense configurado por 21 municípios, passíveis para análises sobre a 
eficiência das políticas educacionais implantadas no Brasil e neste recorte do território e da espacialidade sudeste paranaense.

Quadro 1 - Dados educacionais gerais dos censos 1991, 2000 e 2010

\begin{tabular}{|c|c|c|c|}
\hline Espacialidades & $\begin{array}{c}\% \text { de }+18 \text { anos com } \\
\text { fundamental completo } \\
\text { em } 1991\end{array}$ & $\begin{array}{c}\% \text { de }+18 \text { anos com } \\
\text { fundamental completo } \\
\text { em } 2000\end{array}$ & $\begin{array}{c}\text { \% de + } 18 \text { anos com } \\
\text { fundamental completo } \\
\text { em } 2010\end{array}$ \\
\hline Brasil & 30,09 & 39,76 & 54,92 \\
\hline Paraná & 29,11 & 41,95 & 55,53 \\
\hline Espacialidades & $\begin{array}{l}\%+18 \text { anos com } \\
\text { médio completo } \\
\text { em } 1991\end{array}$ & $\begin{array}{c}\%+18 \text { anos com } \\
\text { médio completo } \\
\text { em } 2000\end{array}$ & $\begin{array}{c}\%+18 \text { anos com } \\
\text { médio completo } \\
\text { em } 2010\end{array}$ \\
\hline Brasil & 0 & 30,84 & 44,91 \\
\hline Paraná & 0 & 31,75 & 44,90 \\
\hline Espacialidades & $\begin{array}{c}\% \text { de }+25 \text { anos com } \\
\text { superior completo } \\
\text { em } 1991\end{array}$ & $\begin{array}{c}\% \text { de }+25 \text { anos com } \\
\text { superior completo } \\
\text { em } 2000\end{array}$ & $\begin{array}{c}\% \text { de }+25 \text { anos com } \\
\text { superior completo } \\
\text { em } 2010\end{array}$ \\
\hline Brasil & 5,75 & 6,77 & 11,27 \\
\hline Paraná & 5,53 & 7,03 & 12,75 \\
\hline
\end{tabular}

Fonte: Atlas Brasil/2013, Dados da Pesquisa, 2019.

Na Tabela 4, apresentam-se os dados de espacialidades dos indicadores educacionais da média nacional, do Estado do Paraná e do território sudeste paranaense, sobre o ensino fundamental completo, no espaço de tempo dos 20 anos, coletados nos 3 censos (1991,200 e 2010) realizados pelo IBGE, no Brasil.

Observa-se que esses indicadores, sobre a escolaridade do ensino fundamental completo, incidiram certo grau na evolução, principalmente, nota-se que os dados apontam para todos os municípios que ocorrem melhoras significativas. Em alguns municípios quase que dobraram ou triplicaram os valores, como se observa os indicadores que estavam abaixo de $10 \%$ como em: Antônio Olinto aumentou 440,12\%, Cruz Machado 354,39\%, Fernando Pinheiro 395,88\%, Ipiranga 230,82\% e em São João do Triunfo aumentou 257,54\%.

Entre os municípios de maior população no território como: Imbituva a melhora foi de 146,42\%, Irati foi de 105,00\%, Prudentópolis a melhora foi de $175,25 \%$, São Mateus do Sul, a melhora foi de $295,52 \%$ e em União da Vitória melhorou a média em $67,45 \%$. Esses dados demonstram a mudança para melhor no ensino fundamental nestes municípios. 
Tabela 4 - Dados dos indicadores educacionais de ensino fundamental completo

\begin{tabular}{|c|c|c|c|}
\hline Espacialidades & $\begin{array}{c}\% \text { de }+18 \text { anos com } \\
\text { fundamental completo } \\
\text { em } 1991\end{array}$ & $\begin{array}{c}\% \text { de }+18 \text { anos com } \\
\text { fundamental completo } \\
\text { em } 2000\end{array}$ & $\begin{array}{c}\% \text { de }+18 \text { anos com } \\
\text { fundamental completo } \\
\text { em } 2010\end{array}$ \\
\hline Brasil & 30,09 & 39,76 & 54,92 \\
\hline Paraná & 29,11 & 41,95 & 55,53 \\
\hline Antônio Olinto & 5,55 & 14,87 & 28,09 \\
\hline Bituruna & 13,51 & 23,46 & 38,65 \\
\hline Cruz Machado & 8,31 & 17,15 & 33,76 \\
\hline Fernandes Pinheiro & 6,56 & 17,32 & 32,53 \\
\hline General Carneiro & 12,55 & 24,02 & 37,36 \\
\hline Guamiranga & 11,02 & 16,11 & 31,68 \\
\hline Imbituva & 13,29 & 20,48 & 32,75 \\
\hline Ipiranga & 9,44 & 18,99 & 31,23 \\
\hline Irati & 23,19 & 32,26 & 47,59 \\
\hline Ivaí & 11,64 & 19,57 & 33,97 \\
\hline Mallet & 15,71 & 24,59 & 43,34 \\
\hline Paula Freitas & 16,39 & 26,39 & 41,84 \\
\hline Paulo Frontin & 16,47 & 24,39 & 41,22 \\
\hline Porto Vitória & 16,54 & 21,44 & 39,10 \\
\hline Prudentópolis & 13,44 & 21,02 & 36,86 \\
\hline Rebouças & 12,04 & 23,59 & 37,92 \\
\hline Rio Azul & 12,59 & 22,23 & 35,21 \\
\hline São João do Triunfo & 8,15 & 16,87 & 29,14 \\
\hline São Mateus do Sul & 17,02 & 30,22 & 47,74 \\
\hline Teixeira Soares & 15,11 & 28,54 & 38,03 \\
\hline União da Vitória & 33,58 & 43,17 & 56,23 \\
\hline Média do território & 13,91 & 23,18 & 37,82 \\
\hline
\end{tabular}

Fonte: Atlas Brasil/2013 - Dados da Pesquisa, 2019.

Segundo PAULA FERREIRA (2017), fatores combinados também fazem com que grande parte dos jovens não conclua o ensino médio até os 19 anos. A pesquisa mostra que em 2005 apenas 41,4\% dos jovens de 19 anos haviam se formado na etapa. Em 2015, o índice era de $58,5 \%$, muito abaixo da meta estabelecida para a educação do ensino médio que era de $74,5 \%$. Essa pesquisa é uma realidade que se reproduz neste território do sudeste paranaense.

Na Tabela 5 são apresentados indicadores educacionais de ensino médio completo do território sudeste paranaense. Os indicadores sobre o ensino médio completo, entre os 15-17 anos, baseados em dados dos três censos, realizados pelo IBGE (1991, 2000 E 2010), apontam melhoras significativas neste subitem, destacando-se aqui os municípios menores como: Antônio Olinto melhorou 606,66\% Fernandes Pinheiro 420,23\%, Guamiranga 237,95\%, Paula Freitas, melhorou 423,74\%, Paulo Frontin, 240,48\%, Porto Vitória os indicadores melhoraram 243,70\%. 
Tabela 5 - Dados dos indicadores educacionais de ensino médio completo

\begin{tabular}{|c|c|c|c|}
\hline Espacialidades & $\begin{array}{l}\%+18 \text { anos com } \\
\text { médio completo } \\
\text { em } 1991\end{array}$ & $\begin{array}{l}\%+18 \text { anos com } \\
\text { médio completo } \\
\text { em } 2000\end{array}$ & $\begin{array}{c}\%+18 \text { anos com } \\
\text { médio completo } \\
\text { em } 2010\end{array}$ \\
\hline Brasil & 17,91 & 24,67 & 37,89 \\
\hline Paraná & 17,33 & 26,01 & 38,52 \\
\hline Antônio Olinto & 2,10 & 8,26 & 16,10 \\
\hline Bituruna & 6,89 & 11,44 & 20,15 \\
\hline Cruz Machado & 3,77 & 8,40 & 18,89 \\
\hline Fernandes Pinheiro & 3,36 & 8,78 & 17,48 \\
\hline General Carneiro & 4,83 & 10,91 & 21,99 \\
\hline Guamiranga & 5,77 & 9,34 & 19,50 \\
\hline Imbituva & 8,24 & 11,77 & 19,68 \\
\hline Ipiranga & 4,33 & 9,33 & 17,34 \\
\hline Irati & 13,61 & 18,96 & 31,00 \\
\hline Ivaí & 5,89 & 10,70 & 20,01 \\
\hline Mallet & 9,18 & 12,70 & 29,73 \\
\hline Paula Freitas & 4,38 & 12,50 & 22,94 \\
\hline Paulo Frontin & 7,83 & 13,31 & 26,66 \\
\hline Porto Vitória & 6,75 & 9,06 & 23,20 \\
\hline Prudentópolis & 7,52 & 12,97 & 25,03 \\
\hline Rebouças & 7,39 & 11,32 & 24,21 \\
\hline Rio Azul & 6,93 & 10,80 & 19,60 \\
\hline São João do Triunfo & 3,60 & 8,47 & 15,35 \\
\hline São Mateus do Sul & 10,64 & 18,01 & 30,14 \\
\hline Teixeira Soares & 8,51 & 15,86 & 24,12 \\
\hline União da Vitória & 17,93 & 25,91 & 36,64 \\
\hline Média do território & 7,12 & 12,32 & 22,85 \\
\hline
\end{tabular}

Fonte: Atlas Brasil/2013, Dados da Pesquisa, 2019.

Entre os municípios com maior população no território sudeste paranaense, destaca-se: Imbituva melhorou em 20 anos 138,83\%, Irati 127,77\%, Prudentópolis 232,44\%, São Mateus do Sul 183,27\% e União da Vitória a melhora dos indicadores foi de 104,35\%.

Por fim, os indicadores educacionais de nível superior completo do território sudeste paranaense, são apresentados na Tabela 6. Os dados estatísticos, organizados nesta tabela apontam que nesses 20 anos aconteceram algumas melhoras nos indicadores na formação de nível superior nos municípios da região sudeste paranaense. Os municípios com as maiores porcentagens de nível superior foram: Antônio Olinto com aumento de 2.335,71\%, Bituruna com 870,37\%, Cruz Machado com 1.241,37\%, Fernandes Pinheiro com 426,50\%, General Carneiro com 400,00\%, Guamiranga com 2.670,00\%, Ipiranga com 543,33\%, Paula Freitas com 607,54\% e São Joao do Triunfo com 602,08\%. 
Tabela 6 - Dados dos indicadores educacionais de ensino superior completo

\begin{tabular}{|c|c|c|c|}
\hline Espacialidades & $\begin{array}{c}\text { \% de }+18 \text { anos com } \\
\text { superior completo } \\
\text { em } 1991 \\
\end{array}$ & $\begin{array}{c}\% \text { de }+18 \text { anos com } \\
\text { superior completo } \\
\text { em } 2000\end{array}$ & $\begin{array}{c}\text { \% de }+18 \text { anos com } \\
\text { superior completo } \\
\text { em } 2010\end{array}$ \\
\hline Brasil & 5,75 & 6,77 & 11,27 \\
\hline Paraná & 5,53 & 7,03 & 12,75 \\
\hline Antônio Olinto & 0,14 & 0,89 & 3,41 \\
\hline Bituruna & 0,54 & 3,00 & 5,24 \\
\hline Cruz Machado & 0,29 & 1,43 & 3,89 \\
\hline Fernandes Pinheiro & 0,40 & 0,33 & 2,25 \\
\hline General Carneiro & 0,79 & 2,30 & 3,95 \\
\hline Guamiranga & 0 & 0,57 & 2,68 \\
\hline Imbituva & 1,19 & 1,45 & 3,98 \\
\hline Ipiranga & 0,6 & 1,42 & 3,86 \\
\hline Irati & 3,89 & 4,80 & 8,75 \\
\hline Ivaí & 1,05 & 1,43 & 4,02 \\
\hline Mallet & 1,57 & 1,80 & 4,89 \\
\hline Paula Freitas & 0,53 & 1,92 & 3,75 \\
\hline Paulo Frontin & 1,71 & 2,03 & 4,78 \\
\hline Porto Vitória & 1,16 & 1,82 & 3,75 \\
\hline Prudentópolis & 1,20 & 2,47 & 6,14 \\
\hline Rebouças & 1,71 & 2,49 & 5,74 \\
\hline Rio Azul & 1,26 & 2,12 & 4,09 \\
\hline São João do Triunfo & 0,48 & 1,46 & 3,37 \\
\hline São Mateus do Sul & 2,41 & 3,00 & 7,91 \\
\hline Teixeira Soares & 2,15 & 2,83 & 4,95 \\
\hline União da Vitória & 5,49 & 7,24 & 12,54 \\
\hline MÉDIA DO TERRITÓRIO & 1,36 & 2,23 & 4,95 \\
\hline
\end{tabular}

Fonte: Atlas Brasil/2013, Dados da Pesquisa, 2019

Os municípios com maior população no território do sudeste paranaense, apresentam dados que indicam um aumento percentual de pessoas que cursam o ensino superior: Imbituva com melhora na quantidade em $234,45 \%$, Irati com a melhora na quantidade de $124,93 \%$ no nível superior completo, Prudentópolis com a melhora na quantidade de $411,67 \%$ no nível superior completo, São Mateus do Sul com a melhora na quantidade de pessoas no ensino superior for de $228,21 \%$ no nível superior completo e, União da Vitória melhorou a quantidade de pessoas no ensino superior em $128,41 \%$.

Afim de que se possa entender a importância do ensino superior, os municípios com polos em educação superior, como aponta o censo 2010, Irati com 8,75\%, São Mateus do Sul com 7.91 \% e União da Vitória com 12,59\%, são municípios que possuem maior porcentagem entre seus habitantes com a formação superior. Lembrando que a porcentagem de formados em nível superior no Brasil é de 11,27\% e Paraná é de 12,75\%. 
Para se entender a importância do ensino superior, nos municípios com polos em educação superior, como aponta o censo 2010, Irati tem $8,75 \%$ da população com ensino superior, São Mateus do Sul tem 7,91 \% da população com ensino superior e União da Vitória chega a $12,59 \%$ com ensino superior. São municípios que possuem maior porcentagem entre seus habitantes com a formação superior, justamente, por possuírem escolas de ensino superior públicas e particulares. Lembrando que a porcentagem de formados em nível superior no Brasil é de $11,27 \%$ e a do Paraná é um pouco acima de $12,75 \%$.

Por fim, os dados estatísticos produzidos pelos três censos realizados no Brasil, de 1991, 2000 e 2010, apontam que os indicadores sociais e educacionais, como IDHM, demografia, educação de níveis fundamental, médio e superior, ainda necessita de muitos investimentos na área educacional. Estes são necessários para que as pessoas possam aplicar seus conhecimentos no crescimento econômico, social e cultural do território, como forma de assegurar e proporcionar o desenvolvimento comunitário, territorial e regional.

\section{Considerações finais}

Em várias fontes constam que os Indicadores em Educação são questionados, não propriamente pela falta de dados para a construção de indicadores educativos, mas as condições para o uso legítimo dos indicadores. Isto é, estaria havendo uma carência de significação intrínseca e invariante dos indicadores, cujas causas principais seriam: insuficiente contexto teórico-conceitual; suposição de contextos educativos universais; falta de dados que reflitam mudanças estruturais produzidas na própria escola; e pequena integração dos indicadores educativos aos da estrutura socioeconômicas do país. Mas, certamente nos ajudam a compreender e interpretar, por meio de números, a realidade da educação no Brasil.

Os indicadores apresentados neste artigo refletem uma realidade do território Sudeste Paranaense, que de certa, ao longo dos últimos 20 anos, foram mudando a partir da educação, dessa população que vive no território. Mas ainda estão aquém das necessidades existentes para a promoção de desenvolvimento, neste recorte no territorial, e necessitam, sobretudo, de políticas públicas de infraestrutura e de educação. Não bastam políticas de governo, essas acabam com o mandato do governante, é preciso, certamente, de políticas públicas de Estado e com efetividade, ou seja, com eficiência (meios) e eficácia (resultados) necessárias na promoção do desenvolvimento de forma sustentável. 
Dentre tantas políticas públicas e programas de governo, voltados ao desenvolvimento comunitário, territorial e regional, destaca-se aqui na área da educação, que mesma não consegue evoluir sem efetivar os investimentos de infraestrutura na área educacional. Entrementes, os resultados esperados emanam de algum tempo para serem analisados se, os mesmos, melhoraram por meio da área da educação no Território, contribuindo assim para o desenvolvimento: tanto no Brasil, no Paraná e no recorte da espacialidade do Território Sudeste Paranaense.

A partir das exposições dos dados estatísticos, com a evolução e os valores, observa-se que as ações para melhorar a infraestrutura educacional, disponibilizadas no território, existem instrumentos jurídicos e administrativos destinados ao planejamento e à execução concreta de políticas públicas com a finalidade de promover a redução das desigualdades regionais.

Entrementes, as discussões e buscas sobre as abordagens, das mais distintas escalas espaciais, de ação e transformações nas diferentes dimensões setoriais, que estão presentes e que condicionam à formulação das políticas públicas de desenvolvimento, além dos processos de desenvolvimento territorial, regional e comunitário destaca-se a educação como uma reflexão de desenvolvimento e planejamento territorial. A educação é um dos condicionantes aos desafios e contradições geradas, por estruturas montadas na promoção das políticas e processos de desenvolvimento e dimensões dos processos e politicas territoriais rurais e urbanas, que ao longo da história de um território, como o do sudeste paranaense, ainda apresentam as deficiências nos investimentos na capacidade e estrutura educacional para que o território venha a se desenvolver.

\section{Referências}

ALTMANN, Werner. (1981). A temática dos indicadores sociais e sua resultante atual: a qualidade de vida, Indicadores Sociais de Sergipe, Aracaju.

BRASIL. Ministério do Desenvolvimento Agrário - MDA. http://www.sit.mda.gov.br. Acesso em 25/03/2019.

BRASIL. Portal da Cidadania do Governo Federal, 2017, s/p. Disponível em: https://www.gov.br/cidadania/pt-br. Acesso em: 06/08/2018.

FERREIRA, Paula. Educação. Disponível em: https://oglobo.globo.com/sociedade/educacao/nao-concluiram-ensino-medio. Acesso em 12/03/2019.

IBGE (Instituto Brasileiro de Geografia e Estatística). IBGEcidades. Disponível em: http://www.IBGE.gov.br . Acesso em: 04/05/2018. 
JANNUZZI, Paulo de Martino. Indicadores Sociais no Brasil: conceitos, fontes de dados e aplicações. 5. ed. Campinas: Alínea, 2012.

KNOREK, R. Territórios: políticas de desenvolvimento no Brasil e Portugal. Curitiba, CRV, 2017. LIBÂNEO, J.; FERREIRA, J.; SEABRA, M. Educação escolar: políticas, estrutura e organização. 6 ed. São Paulo: Cortez, 2008.

NETO, Joaquim José Soares; JESUS, Girlene Ribeiro; KARINO, Camila Akemi; ANDRADE, Dalton Francisco de Andrade. Uma escala para medir a infraestrutura escolar. Estudos em Avaliação Educacional: São Paulo, volume 24, jan/abril 2013.

SANDRONI, Paulo. Novíssimo Dicionário de Economia, 1999. Editora Best Seller. Disponível em: http://introducaoaeconomia.files.wordpress.com/2010/03/dicionario-de-economiasandroni.pdf. Acesso em: 04/08/2018

SANTAGADA, Salvatore. (2007). "Indicadores Sociais: Uma primeira abordagem social e histórica". Pensamento Plural. Pelotas. Disponível em http://www.ufpel.edu.br/isp/ppgcs/pensamento-plural/edicoes/01/06.pdf. Acesso em 05/05/2018.

SANTOS, Milton. ELIAS, Denise. Fundamentos teóricos e metodológicos da geografia. 5 ed. São Paulo, Editora HUCITEC, 1997.

VIEIRA, Sofia Lerche. Estrutura e Funcionamento da educação básica. Fortaleza: Edições Demócrito Rocha, UECE, 2001. 